\title{
RETHINKING MY POETRY PEDAGOGY: AN AUTOETHNOGRAPHIC SELF-STUDY
}

\author{
B. Campbell \\ Cluster of Media, Languages and Art \\ University of Kwa-Zulu Natal \\ Durban, South Africa \\ e-mail: campbell@ukzn.ac.za
}

\section{ABSTRACT}

In the English discipline within the university where I am a teacher educator of English, I am in the habit of keeping a reflective journal in which I record my observations of my pedagogic practice. In addition, I require that students write post-lecture evaluations on completion of a series of lectures. This autoethnographic self-study examines a collaborative exercise in which the students and I jointly analysed student evaluations as well as my lecture reflections in order to establish the efficacy of a series of poetry lectures and to recommend where I can improve in my practice. Pre-service teacher educators should model good teaching practices and I have always held the belief that my teaching methodology is constructivist and that in the process I am being reflexive and modeling good practice. However, the intended message is not always that which is received in the way anticipated by the lecturer which is what precipitated this study. Whilst reflective practice has been beneficial in my development as a lecturer, I suspected that working collaboratively with the students, in analysing their post-lecture evaluations and my reflections would be of benefit to both parties. This autoethnographic self-study highlights the importance of analyzing lecture reflections along with student evaluations, and with the students themselves and reports on how, when implemented, the suggested changes improved pedagogic practice.

Keywords: reflective practice, collaborative data analysis, constructivism, pre-service teachers, English education

Teaching that matters is not about you or me. It is about us! (Nash 2004, 127)

\section{INTRODUCTION}

I am a teacher educator of English in a school of Education at a university in Kwa-Zulu Natal and it is my habit to reflect after every lecture in an attempt to understand and improve my practice. This study is about finding my voice as a poetry lecturer through analyzing not only my own reflections of teaching poetry but also the students' post-lecture evaluations in a collaborative arts-based self-study. In discussing reflective practice, Schon (1987) makes the 
distinction between 'knowing-in-action', 'reflection-on-action' and reflection-in-action'. Reflection-on-action is the process of one's thinking about action, talking about it and making change and I have always been of the opinion that this, together with reflection-in-action which involves revising one's actions during teaching, must benefit the students as one reflects in order to improve practice.

In addition to the fact that I reflect after every lecture, after a series of lectures, the students always complete an evaluation in which they comment on the course content as well as the delivery thereof. The responses are generally positive in the student evaluations but I suspect that the students often say what they think I want to hear in spite of the fact that the evaluations are anonymous. When analyzing the evaluations, I always do so alone, and recently I received a negative response in which I was accused of deliberately embarrassing the students by questioning those who do not know the answers and that I do this because I am racist. This accusation was very upsetting and I wondered if perhaps I had missed similar accusations with past evaluations by focusing on the positive and dismissing the negative feedback. The accusation was taken very seriously because I was under the impression that the interactive way in which I lecture, models what it is to be a 'good' teacher of English and that through my methodology of engagement, I was connecting with the students and treating all equitably. However, this was obviously not the case, and my intentions and actions were clearly incongruent which is a classic example of when, as Brookfield (1995) notes, teachers' practices do not always mirror their intentions. When commenting on how intentions do not always equate to appropriate actions, Berry $(2008,81)$ states, '... these goals can be inadvertently undermined by the teacher educator's own choice of actions to achieve them'. Perhaps I was undermining the very goals that I strove to achieve?

Fine $(1998,72)$ writes of 'working the hyphens' which she describes as 'creating occasions for researchers and informants to discuss what is and what is not happening within the negotiated relations of whose story is being told, why, to whom, with what interpretation, and whose story is being overshadowed, why, for whom and with what consequence'. In order to work within the space between the students and me I realized that I should allow the students' voices to be heard. I guessed that perhaps, a deeper understanding of how the lectures were received by the students could be gained if the students and I evaluated my reflections and their post-lecture evaluations together. The analysis was represented through the making of a collage in a collaborative self-study arts-based exercise. The reflections of the lecturer and the students' evaluations were examined in an effort to find the point at which they intersected because it was my belief that it was at this point that I would find what needed to be changed in my delivery of poetry lectures. 
It was during this exercise that I realized that I needed to know the students' experiences of poetry and to use these in the approach to my lectures. It struck me that I had no idea as to the students' previous experiences of poetry and that I needed to understand these and to use that information in my approach to the sessions. The intention of this collaborative exercise was to ascertain if I could improve my practice through collaborating with the students and if so, to find ways in which to improve.

The study was underpinned by the following research questions:

- Does collaborating with students in the analysis of lecturer reflections and student postlecture evaluations impact positively on pedagogic practice?

- Did knowing about students’ experiences of poetry impact positively on my classroom practice?

\section{LITERATURE}

In writing about teaching poetry, Wintle $(2011,57)$ notes that as educators, 'we cannot be reflective without taking risks to our practice and we cannot take risks without reflecting'. In reflecting on her experiences as a teacher of poetry she notes that she initially taught poetry using a teacher-centred skills based approach which was exactly the way in which her teachers taught poetry when she was at school. This methodology is in line with that experienced by the majority of the students who responded to my question about how they were taught poetry at school. As a reflective teacher, Wintle (2011) realized that this was not effective, and she makes suggestions as to how teachers should teach poetry in order to be effective. She notes that in teaching poetry one should start with constructing an understanding of the context of the poem and try to make a link between this and the students' lives. It thus follows that the selection of poems is crucial in the success of a lesson, as the students need to see the link between the poems and their own lives. The response to the poem will thus, firstly be on an emotional level and the understanding of the language issues should then follow. Wintle (2011) also advocates that the poetry sessions start with the exploration of context and my way of doing this would be through asking leading questions. Whilst I make use of questioning as a lecturing method in my English literature pre-service teacher education lectures, I am never sure of the effectiveness of this strategy. The reason behind this technique is that I believe that to be interactive is to encourage students to think critically about the text under discussion and to open it to their meanings. Through this, I am working in collaboration with the students.

This methodology is underpinned by Vygotsky's sociocultural theory, as is this study 
because 'it is founded on the premise that learning is social in nature and that language plays a key role in learning, and while producing language, students use and learn this language as a mediator between their own and other's understandings of notions or actions' (Allahyar and Nazari 2012, 89). Likewise, Van Boxtel (2000) makes the point that socio-cultural theory revolves around the notion that as knowledge construction is happening in the interaction with others, language and culture are interceding. This is important in the context in which I am lecturing as the student population is diverse and there are many cultures at play. Moodley (2014) comments on the interventions that have been out into place to assist students and to increase student throughput and he notes that the general perception seems to be that there is something wrong with the students. He writes of an initiative that was not undertaken to 'fix' the students. Lectures were conducted in such a way that there was an increase in student/lecturer engagement and student/student engagement and this resulted in improved performance. The students were thus engaging in activities and Hall and Murphy (2009, ix) note that from a socio-cultural perspective, pedagogy is what is salient to people as they engage in activity and develop competence in the practice in question'. Through engagement with the students, collaborative knowledge construction is happening and Zeki and Guneyli (2014) state that to teach in a way which is constructivist is to bring about a change in approaches, methods and roles and also that meaning-making should have as its base, the existing knowledge and beliefs alongside new knowledge and experience. However, this is not to say that the educator should not have input and still needs to provide the necessary facts. The facts give the learners a framework into which to fit their knowledge, skills and experience as constructivism acknowledges the interaction between the social order and people’s experiences.

However, in teaching poetry for example, it does not necessarily follow that because lecturers and students are jointly constructing knowledge, the poems that have been selected will be relevant. Roddy (2004), who is a school teacher of English, writes of experiences in which he chose poems to which he thought his learners would relate. He then taught in a constructivist manner in an attempt to assist his learners in finding their voices and in discovering who they were. He writes of being really excited in the planning phase of the lesson and being of the belief that the learners would love the poem and respond positively. They read the poem on their own and were then told to ask questions or make comments about it. The responses were overwhelmingly negative with bored learners stating that the poet was dead and they battled to connect with his message. The next session went much the same way and Roddy's response was to reflect on the sessions. He then decided to experiment by making the writing of poetry the first activity and for this session, selected the poem 'This 
is just to say' by Williams. The first activity was to request that the learners write their own poems along the same lines. This provided the spring board needed for the learners to connect to the poem. He took note of what the learners' poems said and then carefully chose poems connected with their social realities and the class became enthusiastic in the discussion and analysis thereof. What was different in these sessions is that the teacher chose poems that resonated with the learners' environment and Allahyar and Nazari (2012), make the point that sociocultural theory can be used to explain the effect that culture and history have on the language use of teachers and also that the teacher is a social agent who does not only react to the environment but also acts on it.

Perhaps a way of achieving synergy between what is taught and the environment, is to co-construct the curriculum. In discussing teacher education and pedagogy, Loughran (2007) states that on developing a pedagogy of teacher education, there is a need to look beyond the ability to perform a skill and to critique and analyse the nature of practice in both teacher education and the pre-service teachers. Teacher education will be no more than transmission about practice and the pursuit of technical competency if teacher educators do not see teaching as specialized skills, knowledge and practice. In addition, there should be commitment to confront assumptions to align actions and beliefs, and possibilities should be sought for understanding derived from experience. Whilst it is recommended that one works with the students' experiences, Christodoulou (2014) also argues that without facts, true learning cannot take place. As knowledge is accumulated we form a knowledge base on every topic to which we are exposed and this knowledge base is the basis for schema that refers to all knowledge about a topic. Many schemata are thus built and the students then have some framework within which scaffolding can take place and onto which they can hook experiences. With nothing on which to build, what is gleaned and assumed and conceptualized by the learners must surely be very shallow. Christodoulou $(2014,21)$ also notes that factual knowledge has to be integrated with the skills of creativity, problem solving and analysis as ‘knowledge progression depends upon knowledge accumulation' and 'good analytical knowledge depends on a body of knowledge and not on abstract advice'. Thus, it is not about teaching less but about teaching differently.

I am mindful of the fact that I am lecturing pre-service teachers and believe that I should be modeling effective teacher practices that are student centred. This is not to say that I expect students to re-enact my way of teaching because, as espoused by Berry (2008), the students should be allowed to find their own way. It is also my belief that when students are encouraged to participate in class and are involved in the construction of their knowledge, meaningful learning happens. I practice reflexive pedagogy and my understanding of this is 
that it is explicit teaching practice in which there is communication between students and lecturers and we negotiate meaning together in class. Mgqwashu (2000) writes that because the demographics of universities has changed, the way in which lectures are delivered also has to change. He advocates reflexive practice as a means of presenting lectures so as to accommodate all of the students. To teach in a constructivist manner is an attempt to do this and Jonassen (1997) has identified eight characteristics of constructivism. Firstly, educators must acknowledge that there are multiple ways in which to represent reality and that the real world is complex and must be represented as such in the classroom. In addition, attentive reflection which acknowledges both context and content should be encouraged in an environment where there is joint construction of knowledge. It is important to acknowledge the students' backgrounds, and encouraging the co-construction of knowledge is one way in which this can happen in the classroom. However, not all knowledge is co-constructed. As discussed, the teacher must teach the facts with which the learners are not familiar and then bring these into the existing framework of the students' knowledge. To not teach anything new will equate to a very shallow lesson with little or no new knowledge. What must the lecturer then bring to the lecture? Berry (2000) identifies conflicts in teacher education and the first of these is telling and growth. The question that arises here is: how much does one tell the students versus the extent to which we allow them to find out for themselves and to grow as both teachers and researchers? I think that it is about striking the balance between being the authoritative teller teaching and encouraging self-inquiry. Whilst it is important to value and re-construct the experiences of both the lecturer and the students, the lecturer must guard against the session becoming too self-centred and must ensure that only relevant experiences are shared and that the students also have the chance to tell their stories. It is important to model this behavior, as it will reinforce the idea of learner-centred teaching and the students will learn how to encourage all participants in a class to value the experiences of others. In her study, Wintle (2011) states that a teacher must be prepared to take risks and to explore poems with the students in order to jointly create meaning rather than coming into the classroom with all the answers. However, in my practice, I have realized that as the lecturer, I need to proceed with caution when practising constructivism and reflexive pedagogy as some students can feel intimidated when asked to participate as experienced in my lecture. Wintle (2001) also suggests that to launch straight into language issues when teaching poetry can intimidate students and she advocates that these be left until last. In her reflections, of school teaching, she notes that once the learners understood the context of the poems and related them to their own lives, the language analysis of the poems followed naturally. 


\section{METHODOLOGY}

This autoethnographic self-study was about finding my voice as a poetry lecturer through an arts-based collaboration with my students who were integral to the study, as self-study is not a selfish endeavour and 'the self can only exist in relationship to others' (Pithouse, Mitchell and Webber 2009, 74). Clandinin and Connelly (2000) note that when one is writing about 'I', we are making links with 'them', which was my intention in this study. Pithouse et al. (2009) are in agreement with the observation that without the participation of others there is no selfstudy. The term self-study indicates that one is drawing directly from personal experience and it must therefore be applicable to what one does and can inform and transform practice as noted by Samaras (2001). In answering the question as to why self-study research is conducted, she notes that a reason is personal professional accountability and that a self-study researcher will initiate and study her own inquiry in the classroom. Pithouse, Mitchell and Weber (2009) note that self-study is critical in social action and that to change ourselves and our situations, we have to know about ourselves as teachers and teacher educators whilst Dinkelman (2003) views self-study as a way of not only encouraging reflection but as an approach to teacher education. What becomes obvious in looking at these definitions is that to be engaged in self-study is to have made a conscious decision to gain an understanding about what is going on within one's classroom in an attempt to understand oneself as a teacher and that there are various ways in which this can be achieved. The other aspect of self-study that becomes clear in these definitions is that this method involves others and is not only about the self in the classroom. The word self is often misconstrued and the belief is that research will be a study of self when it is, in fact, the self 'doing the study and is in practice' (Hamilton and Pinnegar 2004, 12). Thus, rather than identifying the issues myself, I involved my students by asking that they engage in a pre-lecture activity as well as post-lecture evaluations, and by involving them in the analysis of the data.

In my reflection after the racist accusation, I noted that I was going to ask that a group of students give me their interpretation of the post-lecture evaluations so as to make the process more objective than it is when I analyse them on my own. My reflections and experiences were being connected to the students' wider cultural, political and social issues and the selfstudy is thus autoethnographic as Theoharis (2007) notes that in an autoethnographic study, other participants are a part of the study along with the researcher. In addition, it is not only my story and experiences that will be heard but those of the students and Hamilton et al (2009, 26) make the observation that 'autoethnographers tend to embed a story within a story, thereby providing a meta-narrative'.

This study allowed me to explore my teacher educator self which is my story and in 
doing so and working with the students' I was weaving a narrative that included them and their voices were thus also heard.

The process of data analysis was that I initially collated all of the post-lecture responses into one document by simply copying students' comments verbatim. Four volunteers from the class and I then sat together and as I read the responses out, they paged through magazines and tore out pictures or words that they felt were relevant to what they had heard. After this exercise, I left the room as the students voiced that they felt freer to have honest discussion about their pictures and words if I were not present. Students discussed their choice of pictures and words, and compiled a collage. I was then invited to rejoin the group and they explained the collage to me. The reason for choosing a collage to represent the data was that students do not always like to write and I wanted the activity to be interesting and different. 'Collage portraits provide the opportunity to include marginalized voices and encourage a range of linguistic and non-linguistic representations to articulate authentic lived experiences' (Gerstenblatt 2013, 294).

In discussing their choice of pictures, the participants were going backwards, forwards, inwards and outwards as espoused by Clandinin and Connelly (2008) whilst justifying their choice of images and I am of the opinion that had I been present during this process, I would have learnt a lot more about my pedagogic practice. I feel that if, as the researcher, I ask for feedback about my sessions and then interpret the responses without feedback from the students, I am working outside the space in which dialogue and understanding should happen. This exercise was an attempt to work within this space and was a departure from the scenario in which the researcher analyses the data and then represents it. Gerstenblatt (2013) states that the researcher must find the balance between the piece that has been created to represent the data and the voices that the data represents. What was different in this exercise is that the collage was created by the participants and not by the researcher. Pinar (2004) describes the space in which the artist-researcher-teacher meets as a/r/t. In the collage exercise we had a scenario that included artist-researcher-teacher-student and the students were the most important component as they were now making decisions as to how they would represent their own voices in the space where the subjective and the objective meet (Leavy 2004). The data was representing my voice as well as those of the students and Ellis and Bochner (2000) identify this parallel exploration of experiences as a feature of autoethnography.

It was whilst the students were explaining the collage to me and chatting about their school poetry experiences, that it struck me that in order to change the way in which I teach, I needed to understand the students' prior experiences of the genre and to then use that information for my own teaching and it was this that became the starting point for the poetry 
lectures the following year. Dinkelman (2003) states that to be engaged in self-study will help practitioners to know more about their teaching situations and also to gather general knowledge that can be used in the classroom which were my objectives in asking that the students tell me about their experiences of poetry which were then used to inform my classroom practice.

Language lecturers are able to draw on a range of rich resources and having an awareness of students' backgrounds can make the learning more relevant and meaningful as one can make informed choices about subject content as well as which method will best suit the group. Cross (2010) notes that not many studies have explored the notion that the impact of lived experiences is important to cognitive development and in asking the students about their experiences, I was hoping to make my content more relevant to their lives and thus aid their development. It was my belief that if the content were relevant to the students, they would receive the lectures favorably which would mean that the exercise had benefitted the way in which I deliver my lectures. Their responses gave me insight into their experiences of poetry and in the first lecture I briefly discussed the responses, and informed the students that the way in which I would be approaching the lectures might disrupt their experiences and I then explained my approach - thus orientating them to the methodology. I hoped that alerting them to my methods, it would encourage participation and that they would realise the rationale behind the methodology. After the series of poetry lectures in which I changed my approach, the students wrote post-lecture evaluations which were analysed. These evaluations, together with the collage exercise were very useful as the collage exercise pointed out what should change in my practice and the student evaluations confirmed that the changes had been effective. In a study such as this, all parties should benefit and in order to ascertain whether the collage exercise had been meaningful to the students and if it was something worth repeating in the future, I asked that they give me feedback about how they had experienced the exercise.

\section{FINDINGS}

The findings indicate that the collaborative collage exercise was beneficial to me and indicated where I could improve on my practice which, in turn, benefitted my students. When the participants discussed the collage with me, they explained why they had included certain pictures and words in order to represent their peers' post-lecture evaluations which gave me pointers as to which aspects of my poetry pedagogic practice needed to be changed and what was working. The objective of the exercise was to use the student's post-lecture evaluations with my reflections in order to improve my practice but an added benefit was that the students 
who participated in the exercise also benefitted from the collaborative exercise.

The way in which the exercise benefitted my practice was firstly, that it confirmed a lot of what I had written in my post-lecture reflections and I now had an objective view as to the efficacy of my classroom practice. However, the most useful finding was incidental when, through listening to the students chatting about poetry, I realized that I needed to start my lectures by getting to know about their experiences of the genre. In the exercise in which the students thought about their poetry experiences, my suspicions that, in the main, their experiences of poetry were not pleasant were confirmed. Seventy-three per cent of the group of the group of 54 had a word that was negative and some of the words that were used were 'boring', 'gloomy', 'hectic', 'horrible', 'confusing' and 'torture'. The second question asked about the methodology and the responses showed that 87 per cent were used to a teachercentred methodology where the learners were expected to learn what had been taught and then to regurgitate this back to the teacher. This confirmed that the way in which I lecture poetry is very different to their experiences and it is no surprise that some of the students felt threatened by my way of delivering a lecture. Some of the students elaborated and a sample of the responses are as follows:

- $\quad$ The way in which I was taught poetry at school was very teacher centred. The teacher would take control of the class and the lesson was basically spoon feeding us the content of the entire poem. Learners were not given the opportunity to analyse the poem on our own and give our interpretation and thoughts.

My way of delivering a poem is very different and the students are expected to make sense of the poem and do the analysis. This explains why some of the students felt threatened on being handed this task and I had, through the collage exercise, realized that I needed to orientate the students to my way of lecturing poetry.

- We took whatever the teacher had taught us and passed our assessments.

In looking at this comment, it is no surprise that the students felt threatened by my way of lecturing as I made it clear that they were expected to bring their own opinions to the assessments which was new to some of the students and I was putting them under pressure to do something which they had never experienced in poetry.

The above comments express that the students were not given the opportunity to explore the poems themselves and to form their own opinions as the teacher's ideas and interpretations were imposed on them. I also doubt that the poems were in the context of the learners' lives as advocated by Wintle's (2001) observations about allowing the students to make sense of the poems and relating them to the contexts of their lives. I am of the opinion that the way in which the majority of students responded, when asked about their poetry experiences, gave me insight into their attitudes toward poetry. Had it not been for the collage exercise I would 
not have started the lectures by asking that they talk about their experiences and I would not have been aware that it was not my way of lecturing that had to change but how I introduced the genre, that needed changing. I had been lecturing in a way that was contrary to the students' experiences, and I could now prepare them for the fact that my way of teaching differed from the majority of their experiences. Changing my approach to the lectures was useful for different purposes as they encouraged the students to think about their attitudes to experiences of poetry and I used them to inform how I would begin my lectures. The students were alerted to the fact that they would be encouraged to find their voices as discussed by Roddy (2004) and that the lectures would not be spoon-feeding the analysis of the poems.

In contrast to the students' school experiences of poetry, in their evaluations on their experiences of the three sessions in which they were actively involved, it is obvious that the majority of the students enjoyed the sessions with 94 per cent of respondents having positive comments. Some of the responses are as follows:

- I liked that you walked around and spoke to us all the time

- The session was very interactive

- Well done - as a white woman you dealt well with the realities in a township

- I will apply your teaching methods in my classroom

- $\quad$ I liked the fact that we could discuss and participate in lectures

- $\quad$ She helped me to understand

- I like that she facilitates the lecture and is not in charge

- $\quad$ Created interesting discussions

- $\quad$ The teaching style gave me the chance to be critical of the text in different ways

- I had fun.

The post-lecture evaluations point to the fact that the student-centred question and answer reflexive methodology was, in the main, successful. The students also recognized I was facilitating the sessions and guiding them rather than dominating the classroom and I believe that they felt relaxed about this because I had asked them to confront how they had been taught poetry and alerted them to the fact that my approach was different. The comments made me confident that I had found the space between telling and growth as identified by Berry (2008) and also that my methodology had the elements of socio-constructivism as espoused by Van Boxtel (2000), Hall and Murphy (2009) and Zeki and Guneyli (2014). The comments were positive and the students appeared to enjoy the lectures, and appreciated that what was discussed represented their contexts.

In my post-lecture reflections, I noted that what pleased me was the observation that as a white woman I dealt well with the realities of the township and perhaps, I had displayed that I 
was interested in, and valued the students' experiences. It is important to me that I connect with the students and bridge the gap between myself and them. To ask the students' about their experiences and to orientate them to my way of dealing with poetry meant that I had made it my business to explore their contexts as advocated by Wintle (2011). The students come from very diverse backgrounds and I could plan the lectures with their experiences in mind. My post-lecture reflections note that the fact that the students and I had engaged in the collaborative exercise the year before, and that I had the benefit of their input, was instrumental in the improved lectures. I don't know that I would have made the changes had I not connected to the students' contexts before-hand.

The findings on the comments after the collage exercise were particularly interesting to me as the students appreciated and enjoyed being part of the process and there were unexpected benefits for them. Participant one noted that the value of the experience lay in the fact that the exercise was cooperative and stated '... it is also very important to work with others, both students and teachers/lecturers, to incorporate different views so as to get a holistic picture that can be addressed afterwards'. The comment indicates that the collaborative data analysis was a successful exercise from which students and lecturers can learn. She also commented on the fact that real comments were used and that through the exercise they were able to 'sift out the do's and don'ts of teaching through the experience of the lecturer in a real life setting'. This lived experienced was obviously effective and the student saw value in the collaborative exercise which is a sentiment shared by participant 2 who made the following observation: '... it gave me things to reflect on as an upcoming teacher. Especially the do's and don'ts for an English language teacher.'

Participant 3 noted that to construct the collage was fun as it allowed 'us to express something as supposedly straight-forward as module evaluations in a completely different medium'. She also stated that they could apply what they learned from the exercise in their own classrooms and improve their own teaching. Savas and Nuutinen (2003) write about the importance of the interpretation and meaning-making processes. A very telling comment is as follows: 'It was also very interesting to look at how students interpret every action of the lecturer. You as a teacher might assume you are sending across a certain message, but it turns out that the learners interpreted it completely differently.' This comment is in line with Berry's (2008) observation that intention does not always equate appropriate action. Therefore we also have to be conscious of the words we use and the actions we take. This observation gives me hope that when this student is teaching, she will be mindful of the fact that it is important to keep checking whether or not the message that is received is that which is intended. After this exercise, I will certainly be mindful of this in my lectures. At the end of 
his reflection, Participant 4 wrote: '.. Last but not least, it was a humbling experience to be afforded the opportunity to evaluate and critique you constructively in your capacity as a lecturer without fear of being silenced and intimidated'. This comment made me aware that the student appreciated being part of the process and felt free to state exactly what was on his mind without fear. The comment also indicates that the students and I were 'working the hyphens' (Fine 1998, 72) which was my intention. Thus in this case, my intentions and actions were aligned. In being reflective and then working with the students, I had taken a risk (Wintle 2011) and it was noted and appreciated by the student. I am aware of the fact that I am a teacher educator and thus need to model good practice and the comments confirm that to work in collaboration with the students was beneficial not only to my growth as a teacher educator but to the students.

An added benefit arising from this exercise is that the participants are all going to be teachers of English and that when they get into their own classrooms they will be aware of the importance of working in collaboration with their learners. 'The very process of self-study itself changes its practitioners and their situations. Seeing this differently can prod us to take action' (Pithouse, Mitchell and Webber 2009, 48), and I needed to take action on issues that were important to the students as well as to me in my role as an English teacher educator.

\section{CONCLUSIONS}

The findings lead me to conclude, firstly, that in rethinking my poetry pedagogy, I had found my voice through collaborating with the students. Secondly, within the time that the study spanned, I successfully bridged the gap between the students and me and that to achieve this, did not require major changes in my practice. Thirdly, I came to the realization that to improve my pedagogic practice, it is not enough to engage in reflective practice and to ask that students' complete post-lecture evaluations. The study highlighted that to work in collaboration with students, means that their voices are heard and that one needs to listen to these voices and align pedagogic practice accordingly in order to successfully bridge the gap between 'us' and 'them'.

\section{REFERENCES}

Allahyar, N. and A. Nazari. 2012. Potentiality of Vygotsky's sociocultural theory in exploring the role of teacher perceptions, expectations and interaction strategies. WoPaLP 6: 79-92.

Arend, C., P. Beets and L. Frick. 2010. Reflection as learning about the self in context: Mentoring as catalyst for reflective development in pre-service teachers. South African Journal of Education 30: 421-437.

Berry, A. 2008. Tensions in teaching about teaching. The Netherlands: Springer. 
Brookfield, S. D. 1995. Becoming a critically reflective teacher. San Fransisco: Jossey-Bass.

Clandinin, D. and F. Connelly. 2000. Narrative inquiry. Experience and story in qualitative research. San Francisco: Jossey-Bass.

Christodoulou, D. 2014. Seven myths about education. New York: Routledge.

Dinkelman, T. 2003. Self-study in teacher education: A means and end tool for promoting reflective teaching. Journal of Teacher Education 54: 6-18.

Ellis, C. and A. Bochner. 2000. Autoethnography, personal narrative, reflexivity: Researcher as subject. In Handbook of qualitative research, ed. N. Denzin and Y. Lincoln. London: Sage

Fine, M. 1998. Working the hyphens - Reinventing self and other in qualitative research. http://www.sfu.ca/ decaste/867fall08/867pdfs/handbook_70-82.pdf (accessed 20 March 2014).

Gerstenblatt, P. 2013. Collage portraits as a method of analysis in qualitative research. International Journal of Qualitative Research 12: 294-309.

Hamilton, M. and S. Pinnegar. 2004. Re-visionist self-study: If we knew then what we know now. In Negotiating the diverse landscape of teacher education. $8^{\text {th }}$ International conference on S-Step.

Hamilton, M., L. Smith and K. Worthington. 2008. Fitting the methodology with the research: An exploration of narrative, self-study and auto-ethnography. Studying Teacher Education: A Journal of Self-study of Teacher Education Practices 4(1): 17-28.

Leavy, P. 2009. Method meets art: Arts-based research practice. New York: Guilford Press.

Mgqwashu, E. 2000. University learning: Medium and mode of instruction. Issues in English Studies in Southern Africa 5(2): 63-66.

Moodley, M. 2014. Student engagement: A successful approach to teaching and learning in a thirdlevel engineering module at the University of KwaZulu-Natal. Alternation 21(1): 119-136.

Nash, R. 2004. Liberating scholarly writing. The power of personal narrative. New York: Teachers College Press.

Pithouse, K., M. Mitchell and S. Weber. 2009. Self-study in teaching and teacher development: A call to action. Educational Action Research 17: 43-62.

Roddy, T. 2004. Where's the love? Teaching poetry in high school. California English 9(4): 20-21.

Samaras, A. 2011. Self-Study teacher research: Improving your practice through collaborative inquiry. Thousand Oaks, CA: Sage.

Samaras, A. and A. Freese. 2006. Self-study of teaching practices. New York: Peter Lang.

Schon, D. 1987. Educating the reflective practitioner: Toward a new design for teaching and learning in the professions. San Francisco: Jossey-Bass

Theoharis, G. 2007. Social justice educational leaders and resistance: Toward a theory of social justice leadership. Educational Administration Quarterly 43(2): 221-258.

Van Boxtel, C. 2000. Collaborative concept learning: Collaborative learning tasks, student interaction and the learning of physics concepts. Universiteit Utrecht.

Wintle, P. 2011. Finding yourself in poetry: A reflection on how to encourage student questions through risk taking and shared learning. English in Australia 46(2): 57

Zeki, C. and Z. Gunyeli. 2014. Student teachers' perceptions about their experiences in a student centered course. South African Journal of Education 34(3): 1-11. 